\title{
Halogen-Halogen Bonded Donor-Acceptor Stacks Foster Orthogonal Electron and Hole Transport
}

\author{
Vishnu Vijay ${ }^{\dagger}$, Remya Ramakrishnan ${ }^{\dagger}$ and Mahesh Hariharan* \\ $\dagger$ These authors contributed equally to this work
}

School of Chemistry, Indian Institute of Science Education and Research Thiruvananthapuram

(IISER-TVM), Maruthamala P. O., Vithura, Thiruvananthapuram 695551, Kerala, India.

\section{Supporting Information}

\begin{tabular}{|c|c|}
\hline SI. No & Contents \\
\hline 1. & Syntheses and characterization \\
\hline 2. & Materials and Methods \\
\hline 3. & Table S1. Crystallographic data and refinement parameters for $\mathrm{NIBr}_{2} \mathrm{Ph}$ and $\mathrm{NIBr}_{2} \mathrm{OMe}$. \\
\hline 4. & $\begin{array}{l}\text { Table S2. IQA interaction energies. Total noncovalent interaction energies and its } \\
\text { components are shown. Energies are given in kcal } / \mathrm{mol} \text {. }\end{array}$ \\
\hline 5. & $\begin{array}{l}\text { Table S3. Selected donor-acceptor natural bond orbital interactions with their } \\
\text { corresponding second-order perturbation stabilization energies in } \mathrm{HHB} \text { dimer of } \mathrm{AceCl}_{2} \text {. }\end{array}$ \\
\hline 6. & $\begin{array}{l}\text { Table S4. Selected donor-acceptor natural bond orbital interactions with their } \\
\text { corresponding second-order perturbation stabilization energies in HHB dimer of } \\
\text { AceClBr. }\end{array}$ \\
\hline
\end{tabular}

Page No

7. Table S5. Selected donor-acceptor natural bond orbital interactions with their corresponding second-order perturbation stabilization energies in HHB dimer of $\mathrm{NIBr}_{2} \mathrm{OMe}$.

Table S6. Magnitudes of dipole moments for adjacent dimers of crystal structures.

exhibiting parallelogram-type $\mathrm{X}_{4}$ synthon in (c) $\mathrm{AceCl}_{2}$ and (d) AceClBr. Crystal packing are obtained from previous literature. AceIBr with $\mathrm{I}$ and $\mathrm{Br}$ as peri-halogen substituents also forms Class-1 arrangement.

7. Figure S2. (a) Alternating slip-stacked arrangement and (b) linear arrangement of the side dimer (highlighted with red outline) of $\mathrm{NIBr}_{2} \mathrm{Ph}$ (c) front view and (d) side view of dimeric columns of segregated stacks of $\mathrm{NIBr}_{2} \mathrm{OMe}$ (the mutually perpendicular orientation of the donor and acceptor units are clearly visible as ' $X$ ' shaped units) (e) $\mathrm{NIBr}_{2} \mathrm{OMe}$ arrays perfectly arranged in a plane as viewed along crystallographic $b$-axis (stacking axis).

8. Figure S3. (a) Stacked dimer and (b) one halogen-halogen interaction containing dimer (HHB1) of $\mathrm{NIBr}_{2} \mathrm{Ph}$.

9. Figure S4. QTAIM electron density maps of (a) $\mathrm{AceCl}_{2} \mathrm{HHB}$-dimer and (b) $\mathrm{NIBr}_{2} \mathrm{OMe}$ tetramer showing parallelogram-type $\mathrm{X}_{4}$ synthons. The green and red dots represent BCPs and RCPs respectively. 
8. Figure S5. HHB-dimers of (a) $\mathrm{AceCl}_{2}$, (b) $\mathrm{AceClBr}$ and (c) $\mathrm{NIBr}_{2} \mathrm{OMe}$ with atom labels and depicting $\mathrm{C}-\mathrm{X} \cdots \mathrm{X}$ angles.

9. Figure S6. ESP maps (0.001 isodensity surface) of (a-b) $\mathrm{AceCl}_{2}$, (c-d) $\mathrm{AceClBr}$, (e-f) $\mathrm{AceBr}_{2}$, (g-h) $\mathrm{NIBr}_{2} \mathrm{Ph}$ and (i-j) $\mathrm{NIBr}_{2} \mathrm{OMe}$.

11. Scheme S1. (a) Donor-acceptor arrangement in $\mathrm{NIBr}_{2} \mathrm{OMe}$, (b) symmetric connected acceptor-donor-acceptor (A-D-A) packing that can facilitate continuous electron mobility and (c) donor-acceptor-donor (D-A-D) arrays promoting hole mobility perpendicular to the stacking direction (depicted as red arrow). The blue dotted lines indicate strong intermolecular contacts that facilitate better orbital overlap like X $\cdots \times \mathrm{X}$ bonding.

12. References

\section{Syntheses and characterization:}

All chemicals were obtained from commercial suppliers and used as received without further purification. All reactions were carried out in oven-dried glassware prior to use and wherever necessary, were performed under dry nitrogen in dried, anhydrous solvents using standard gastight syringes, cannula, and septa. Solvents were dried and distilled by standard laboratory purification techniques. TLC analyses were performed on recoated aluminium plates of silica gel $60 \mathrm{~F} 254$ plates $(0.25 \mathrm{~mm}$, Merck) and developed TLC plates were visualized under short and long wavelength UV lamps. Flash column chromatography was performed using silica gel of 200-400 mesh employing a solvent polarity correlated with the TLC mobility observed for the substance of interest. Yields refer to chromatographically and spectroscopically homogenous substances. ${ }^{1} \mathrm{H}$ and ${ }^{13} \mathrm{C}$ NMR spectra were measured on a $500 \mathrm{MHz}$ Bruker avance DPX spectrometer. Internal standard used for ${ }^{1} \mathrm{H}$ and ${ }^{13} \mathrm{C}$ NMR is tetramethyl silane (TMS). High resolution mass spectra (HRMS) were recorded on Thermo scientific Q exactive mass spectrometer using electrospray ionization (ESI) technique.

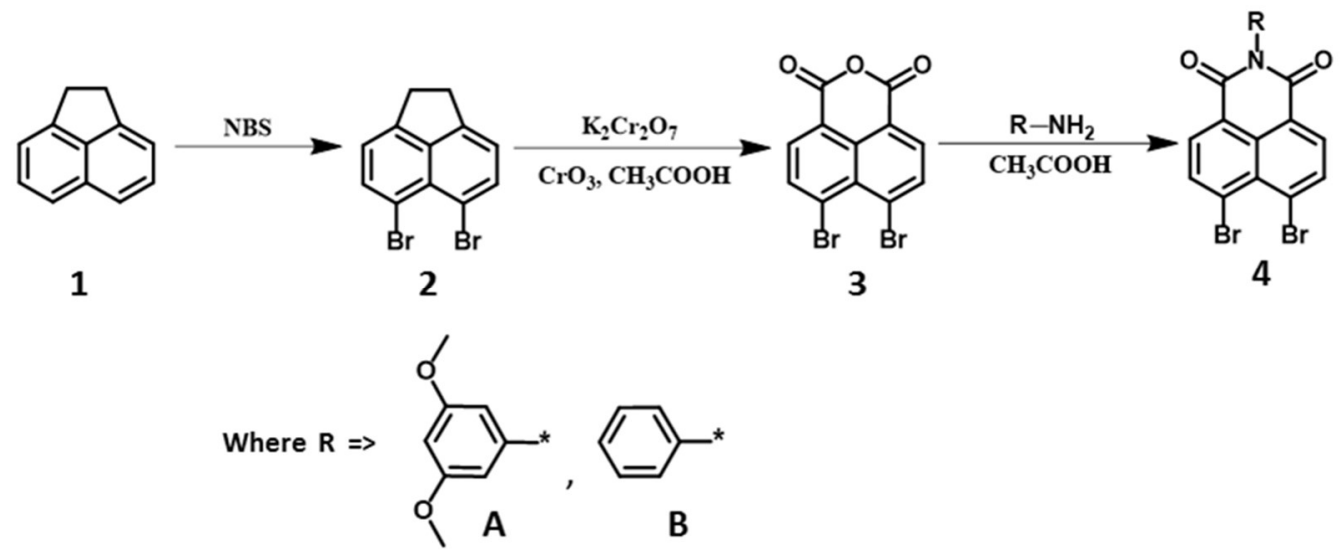

Synthesis scheme: Reaction scheme for the syntheses of $\mathrm{NIBr}_{2} \mathrm{OMe}$ and $\mathrm{NIBr}_{2} \mathrm{Ph}$.

The syntheses scheme was taken from the reported procedure. ${ }^{1,2}$

Synthesis of 2: A suspension of N-Bromosuccinimide in DMF (38.91 mmol) was added into an ice-cold solution of acenaphthene (1) in DMF (12.97 mmol). Reaction mixture was stirred for 3 hours at $0-5{ }^{\circ} \mathrm{C}$ and then for 12 hours at $10-15^{\circ} \mathrm{C}$. The precipitate was filtered, washed with ethanol and dried in vacuum to get a white powder of 5, 6-dibromo acenaphthene ( $\left.\mathrm{AceBr}_{2}\right)$ with $35 \%$ yield (2). Slow evaporation of the product in chloroform: hexane (1:3) at room temperature yielded white transparent crystals of $\mathrm{AceBr}_{2} .{ }^{1} \mathrm{H} \mathrm{NMR}\left(500 \mathrm{MHz}, \mathrm{CDCl}_{3}, \mathrm{ppm}\right)$ : $\delta=7.8115(\mathrm{~d}, \mathrm{~J}=7.5 \mathrm{~Hz}, 2 \mathrm{H}), \delta=7.1105(\mathrm{~d}, \mathrm{~J}=7.5 \mathrm{~Hz}, 2 \mathrm{H}), \delta=3.322(\mathrm{~s}, 4 \mathrm{H}) .{ }^{13} \mathrm{C}$ NMR $(125 \mathrm{MHz}, \mathrm{CDCl})$ : 
$\delta=147.00,141.75,135.77,131.80,120.87,114.31,29.99$. HRMS (ESI) $(\mathrm{m} / \mathrm{z})$ : Calculated for $\mathrm{C}_{12} \mathrm{H}_{8} \mathrm{Br}_{2}$ $[\mathrm{M}+\mathrm{Na}]^{+}: 334.8862$, found: 334.8865 .

Synthesis of 3: A mixture of $2(3.2 \mathrm{mmol}), \mathrm{K}_{2} \mathrm{Cr}_{2} \mathrm{O}_{7}(12.8 \mathrm{mmol}), \mathrm{CrO}_{3}(6.4 \mathrm{mmol})$ and acetic acid was refluxed overnight and then poured into ice water. The precipitate was collected by filtration and washed with water to give product (3). Dil. $\mathrm{HCl}$ was added and filtered. Since the anhydride was insoluble, we continued the synthesis without purification.

Synthesis of 4: 1:3 equivalence of compound 3 and $\mathrm{A}-\mathrm{NH}_{2} / \mathrm{B}-\mathrm{NH}_{2}$ along with acetic acid $(5 \mathrm{~mL})$ and $\mathrm{N}$-methyl2- pyrrolidone $(5 \mathrm{~mL})$ were charged in a flask. The reaction mixture was refluxed for 12 hours. After cooling and adding water, the resulting precipitate was collected and further purified by silica gel column chromatography to obtain $\mathrm{NIBr}_{2} \mathrm{OMe}$ and $\mathrm{NIBr}_{2} \mathrm{Ph}$ in $30 \%$ and $45 \%$ yields respectively. Slow evaporation of the product in ethyl acetate:methanol and chloroform: hexane (1:3) at room temperature yielded crystals of $\mathrm{NIBr}_{2} \mathrm{OMe}$ and $\mathrm{NIBr}_{2} \mathrm{Ph}$ respectively.

NIBr 2 OMe: ${ }^{1} \mathrm{H}$ NMR $\left(500 \mathrm{MHz}, \mathrm{CDCl}_{3}\right): \delta=8.45(\mathrm{~d}, \mathrm{~J}=8 \mathrm{~Hz}, 2 \mathrm{H}), 8.26(\mathrm{~d}, \mathrm{~J}=7.8 \mathrm{~Hz}, 2 \mathrm{H}), 6.55(\mathrm{~s}, 2 \mathrm{H}), 6.3(\mathrm{~s}$, $1 \mathrm{H}), 3.86(\mathrm{~s}, 6 \mathrm{H}) .{ }^{13} \mathrm{C} \mathrm{NMR}\left(125 \mathrm{MHz}, \mathrm{CDCl}_{3}, \mathrm{ppm}\right): \delta=164.30,161.50,137.24,135.80,134.43,130.80,128.75$, 124.80, 106.20, 101.4, 55.30. HRMS (ESI) $(\mathrm{m} / \mathrm{z})$ : calculated for $\mathrm{C}_{20} \mathrm{H}_{13} \mathrm{Br}_{2} \mathrm{NO}_{4}[\mathrm{M}+\mathrm{Na}]^{+}$: 513.9089 , found: 513.9088 .

$\mathrm{NIBr}_{2} \mathrm{Ph}:{ }^{1} \mathrm{H}$ NMR $\left(500 \mathrm{MHz}, \mathrm{CDCl}_{3}\right): \delta=8.45(\mathrm{~d}, \mathrm{~J}=8.0 \mathrm{~Hz}, 2 \mathrm{H}), 8.26(\mathrm{~d}, \mathrm{~J}=8 \mathrm{~Hz}, 2 \mathrm{H}), 7.58-7.54(\mathrm{~m}, 2 \mathrm{H})$, $7.51-7.48(\mathrm{~m}, 1 \mathrm{H}) 7.30(\mathrm{~d}, \mathrm{~J}=8.0 \mathrm{~Hz}, 2 \mathrm{H}) .{ }^{13} \mathrm{C} \mathrm{NMR}\left(125 \mathrm{MHz}, \mathrm{CDCl}_{3}, \mathrm{ppm}\right): \delta=162.20,137.15,134.68$, 132.52, 131.25, 129.70, 128.34, 125.40, 123.80. HRMS (ESI) (m/z): calculated for $\mathrm{C}_{18} \mathrm{H}_{9} \mathrm{Br}_{2} \mathrm{NO}_{2}[\mathrm{M}+\mathrm{Na}]^{+}$: 453.8878, found: 453.8876

\section{Materials and Methods:}

X-ray Crystallography: High quality single crystals of $\mathrm{NIBr}_{2} \mathrm{OMe} / \mathrm{NIBr}_{2} \mathrm{Ph}$ were used for X-ray diffraction experiments. Single crystal was mounted using oil (Infineum V8512) on a glass fiber. All measurements were made on a CCD area detector with graphite monochromated Mo K $\alpha$ radiation. The data was collected using Bruker APEXII detector and processed using APEX2 from Bruker. The structure was solved by direct method and expanded using Fourier technique. The non-hydrogen atoms were refined anisotropically. Hydrogen atoms were included in idealized positions, but not refined. Their positions were constrained relative to their parent atom using the appropriate HFIX command in SHELX-97. ${ }^{3}$ All programs used during the crystal structure analysis are incorporated in the WINGX software. ${ }^{4}$ The full validation of CIF and structure factor of $\mathrm{NIBr}_{2} \mathrm{OMe} / \mathrm{NIBr}_{2} \mathrm{Ph}$ was performed using the checkCIF utility and found to be free of major alert levels. Three dimensional structure S3 visualization and the exploration of the crystal packing of crystals under study were carried out using Mercury 3.5.1..$^{5}$

\section{Computational Methods:}

Ground-state optimized structure, dipole moments and frontier molecular orbitals were calculated at the wB97XD/aug-cc-pVDZ level of theory. ${ }^{6}$ All these computations were performed using the Gaussian 16 suite. ${ }^{7}$ Isodensity plots of frontier molecular orbitals were created with GaussView 5.0.8. ${ }^{8}$

Quantum Theory of Atoms in Molecules (QTAIM) ${ }^{9}$ : The wave function generation for the molecules was carried out at wB97XD/aug-cc-pVDZ level of theory ${ }^{6}$ using Gaussian $16 .{ }^{7}$ Quantum theory of atoms in molecules (QTAIM) analyses helps to understand the description of interatomic interaction in the single crystal X-ray structure. A bond is defined along the bond line between two nuclei, called a bond path, along which electron density is concentrated. The $(3,-1)$ bond critical point $(\mathrm{BCP})$ is a point along the bond path at the interatomic surface, where the shared electron density reaches a minimum. $(3,+1)$ ring critical point $(\mathrm{RCP})$ and $(3,+3)$ cage critical point (CCP) represents critical points in the ring and cage respectively where the electron density is minimum. Using the AIMAll software package, the electron density was integrated over atomic basins according to the quantum theory of atoms in molecules using PROAIM, and the molecular graphs were obtained.

Interacting quantum atoms (IQA) ${ }^{10}$ : IQA approach was done using AIMALL software to understand the nature of intermolecular interactions. Hamiltonian is partitioned into physical atomic and interatomic contributions. The energy decomposition computed using partitioned Hamiltonian is consistent with the topological method of quantum theory of atoms in molecules. The interatomic energy contribution values determine the nature of intermolecular or intramolecular interactions. 
The total interatomic energy $\left(E_{t}^{A B}\right)$ is the summation of interparticle [electron (e) and nucleus (n)] interaction energies, which is given by:

$$
E_{t}^{A B}=E_{n n}^{A B}+E_{e n}^{A B}+E_{n e}^{A B}+E_{e e}^{A B}
$$

Where the electron-electron interaction is the summation of exchange $\left(E_{X}^{A B}\right)$, correlation $\left(E_{C}^{A B}\right)$ and coulomb $\left(E_{\text {Coul }}^{A B}\right)$ potentials

$$
E_{e e}^{A B}=E_{X}^{A B}+E_{C}^{A B}+E_{C o u l}^{A B}
$$

Now, as per IQA, the classical component $\left(E_{c l}^{A B}\right)$ is the union of all the electrostatic terms

$$
E_{c l}^{A B}=E_{n n}^{A B}+E_{e n}^{A B}+E_{n e}^{A B}+E_{C o u l}^{A B}
$$

and the exchange-correlation component consists of all the quantum terms

$$
E_{X C}^{A B}=E_{X}^{A B}+E_{C}^{A B}
$$

Thus, total interatomic interaction energy is decomposed into classical and quantum terms separately

$$
E_{t}^{A B}=E_{c l}^{A B}+E_{X C}^{A B}
$$

Natural bond orbital analyses ${ }^{11,12}$ : The natural bond orbital (NBO) analyses was performed at the wB97XD/augcc-pVDZ level of theory ${ }^{6}$, by means of the Gaussian 16 calculation package. ${ }^{13}$ The orbital donor-acceptor interactions are assessed by probing all possible interactions between occupied (donor) Lewis-type NBOs and unoccupied (acceptor) non-Lewis NBOs by second-order perturbation theory. For each donor NBO (i) and acceptor NBO (j), the stabilization energy $E(2)$ associated with delocalization from the filled NBOs into the unoccupied non-Lewis orbitals is estimated.

Electrostatic Surface Potential ${ }^{14}$ : Electrostatic surface potential (ESP) map illustrates the charge distribution of molecules in three dimension. These maps allow us to visualize variably charged regions of a molecule. Knowledge of the charge distributions can be used to determine how molecules interact with one another. Gaussian supports the cube keyword to generate the cubes separately from the formatted checkpoint file (generated from energy calculation with wB97XD/aug-cc-pVDZ level of theory) using the cubegen utility program. This allows for the generation of electrostatic surface potential mapping of the molecule.

\section{Charge Transport Parameters:}

The reorganization energies are given by the equation:

$$
\lambda_{ \pm}=\left(E_{0}^{*}-E_{0}\right)+\left(E_{ \pm}^{*}-E_{ \pm}\right)
$$

in which $E_{0}$ and $E_{ \pm}$are the lowest energies of neutral and cationic/anionic species respectively. For hole reorganization energy $(\lambda \mathrm{h}), \mathrm{E}_{0} *$ is the energy of a neutral molecule with cation geometry while for the electron reorganization energy $(\lambda \mathrm{e}), \mathrm{E}_{0} *$ corresponds to the energy of the neutral molecule with anion geometry. All the geometries for the calculation of reorganization energies were obtained from optimized structures using wB97XD/aug-cc-pVDZ level of theory from Gaussian 16.

The diagram below represents the potential energy surfaces of the neutral state and the ionic state (cation or anion) for a system with identical molecules. The vertical transitions which leads to the transfer of charge from one molecule to the other is shown in green arrows. The nuclear coordinates of the molecules will not be changed upon the transition, and hence as a neutral molecule become charged, it has the same geometry and vice versa. Thus transition leads to a cation/anion with the geometry of the neutral molecule (with energy $E_{ \pm}{ }^{*}$ ) and a neutral molecule with the geometry of the cation/anion (with energy $E_{0}{ }^{*}$ ) respectively. These molecules then undergo reorganization to reach the optimum geometry. This is the internal reorganization energy, and is the sum of two such reorganizations. 


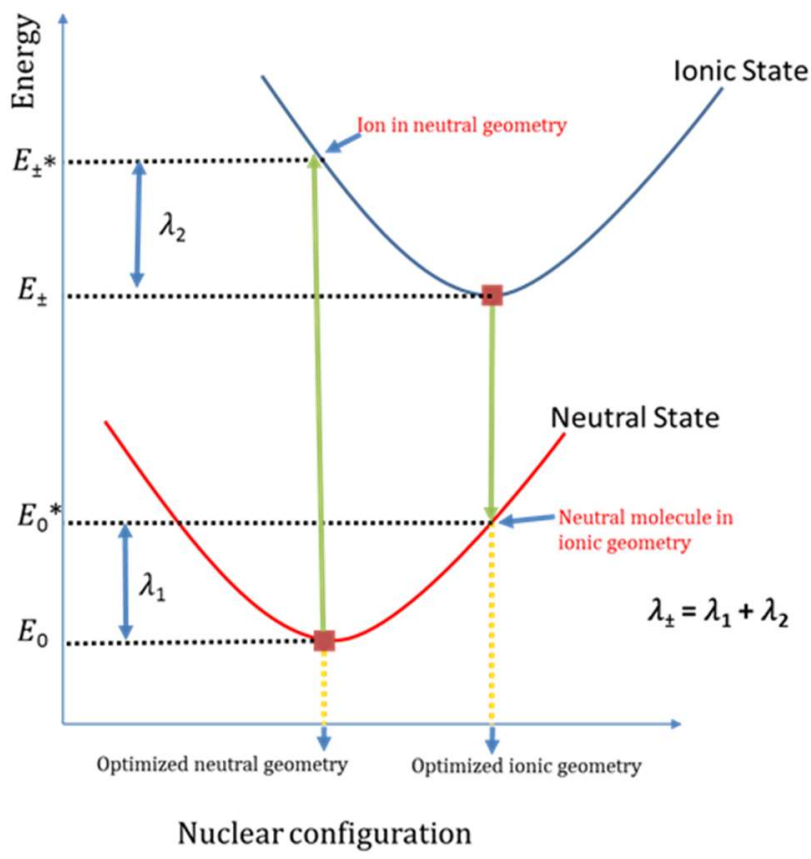

Diagram. Potential energy curves of the neutral state and the ionic state (cation or anion) for a system with identical molecules.

The charge transfer rate, $W_{i}$, which represents the rate of hole/electron hopping to the similar $\mathrm{i}^{\text {th }}$ neighbor ${ }^{15}$ was obtained from the Marcus-Hush equation: ${ }^{16-18}$

$$
W_{\mathrm{i}}=\frac{V^{2}}{\hbar}\left(\frac{\pi}{\lambda k_{\mathrm{B}} T}\right)^{1 / 2} \exp \left(-\frac{\lambda}{4 k_{\mathrm{B}} T}\right)
$$

where $\mathrm{V}$ is electronic coupling between the chromophores, $\lambda$ is the reorganization energy for the respective charge carriers, $\mathrm{k}_{\mathrm{B}}$ is the Boltzmann constant and $\mathrm{T}$ is the temperature $(300 \mathrm{~K})$.

A fixed molecule was taken in the plane of interest and all the dimers formed along with its neighboring molecules were considered for the calculations. For each of these dimers, V and W was calculated. The electron and hole coupling values of molecules within the dimers were calculated from post processed Gaussian 16 output files by employing the CATNIP Tool version 1.9. ${ }^{19}$ For further information regarding how the calculations are done, please refer to reference 19 in Supporting Information. All the calculations were performed at wB97XD/aug-ccpVDZ level of theory on the geometries taken from the crystal structure.

$P_{i}$, the probability of hole/electron transfer to the $\mathrm{i}^{\text {th }}$ neighbor which is given by:

$$
P_{i}=\frac{W_{i}}{\sum_{i} W_{i}}
$$

This was calculated after finding out all the possible hopping paths (nearest neighbor molecules).

Einstein's relation describes drift mobility as follows,

$$
\mu=\frac{e}{2 n k_{B} T} \sum_{i} r_{i}^{2} W_{i} P_{i}
$$

Which is calculated from the values of previously calculated $\mathrm{W}_{\mathrm{i}}, \mathrm{P}_{\mathrm{i}}$ and $\mathrm{r}_{\mathrm{i}}$ (The distance between the centroids of the molecules in a dimer). Where $n$ represents the spatial dimensionality (i.e. 3 ) and $i$ denotes a particular hopping pathway. 
Anisotropic mobility of the crystals was calculated by the following equation:

$$
\mu_{\Phi}=\frac{e}{2 k_{B} T} \sum_{i} W_{i} r_{i}^{2} P_{i} \cos ^{2} \gamma_{i} \cos ^{2}\left(\theta_{i}-\Phi\right)
$$

in which $\gamma_{\mathrm{i}}$ is the angle between the charge hopping pathway and plane of interest. $\theta-\phi$ is the angle between the hopping pathway and the conduction channel. $r_{\mathrm{i}}, \gamma_{\mathrm{i}}$ and $\theta_{\mathrm{i}}$ are obtained from the molecular packing architecture in the organic crystal. All the angles are calculated from the vectors of molecular positions taken from the crystal structures. The calculations corresponding to each step were carried out in Microsoft Excel worksheet. The procedure used for calculating anisotropic mobility is based on the method developed by Han and co-workers. ${ }^{19}$ Please refer to Reference 20 in the Supporting Information for detailed description.

\section{Tables}

Table S1. Crystallographic data and refinement parameters for $\mathrm{NIBr}_{2} \mathrm{Ph}$ and $\mathrm{NIBr}_{2} \mathrm{OMe}$.

\begin{tabular}{|c|c|c|}
\hline Parameters & $\mathrm{NIBr}_{2} \mathrm{Ph}$ & $\mathrm{NIBr}_{2} \mathrm{OMe}$ \\
\hline Formula & $\mathrm{C}_{18} \mathrm{H}_{9} \mathrm{Br}_{2} \mathrm{~N} \mathrm{O}_{2}$ & $\mathrm{C}_{20} \mathrm{H}_{13} \mathrm{Br}_{2} \mathrm{~N} \mathrm{O}_{4}$ \\
\hline Formula wt. & 431.08 & 491.13 \\
\hline Color & Colourless & Yellow \\
\hline Crystal system & Triclinic & Monoclinic \\
\hline Space group, Z & $P-1,4$ & $P 2_{1} / c, 4$ \\
\hline$a, \AA$ & $7.4176(13)$ & $22.089(6)$ \\
\hline $\mathrm{b}, \AA$ & $13.560(3)$ & $4.9601(13)$ \\
\hline c, $\AA$ & $15.705(3)$ & $16.744(5)$ \\
\hline$\alpha$, deg & $98.288(6)$ & 90 \\
\hline$\beta$, deg & $94.828(6)$ & $105.024(8)$ \\
\hline$\gamma$, deg & $98.915(6)$ & 90 \\
\hline$V, \AA^{3}$ & $1535.1(5)$ & $1771.8(8)$ \\
\hline $\mathrm{R}$ factor & 5.79 & 9.56 \\
\hline Temp, K & $296(2)$ & $296(2)$ \\
\hline $\mathrm{d}_{\text {calculated }}, \mathrm{mg} / \mathrm{m}^{3}$ & 1.864 & 1.842 \\
\hline No. of reflections collected & 5393 & 3102 \\
\hline No. of unique reflections & 3404 & 1711 \\
\hline $2 \theta_{\text {max }}$, deg & 45.78 & 41.96 \\
\hline No. of parameters & 415 & 246 \\
\hline$R 1, w R 2,(I>2 s(I))$ & $0.0579,0.1115$ & $0.0956,0.2455$ \\
\hline R1, wR2 (all data) & $0.1114,0.1337$ & $0.1583,0.2965$ \\
\hline goodness of fit & 1.038 & 1.027 \\
\hline CCDC number & 1994860 & 1994859 \\
\hline
\end{tabular}


Table S2. IQA interaction energies. Total noncovalent interaction energies and its components are shown. Energies are given in $\mathrm{kcal} / \mathrm{mol}$.

\begin{tabular}{|c|c|c|c|c|c|c|c|c|c|}
\hline & \multicolumn{3}{|c|}{$\mathrm{AceCl}_{2}$} & \multicolumn{3}{|c|}{ AceClBr } & \multicolumn{3}{|c|}{$\mathrm{NIBr}_{2} \mathrm{OMe}$} \\
\hline Interactions & $E_{t}$ & $\mathrm{E}_{\mathrm{xc}}$ & $\mathrm{E}_{\mathrm{cl}}$ & $E_{t}$ & $E_{x c}$ & $\mathrm{E}_{\mathrm{cl}}$ & $E_{t}$ & $\mathrm{E}_{\mathrm{xc}}$ & $\mathrm{E}_{\mathrm{cl}}$ \\
\hline X-X (Intermolecular) & -3.012 & -6.212 & 3.200 & -6.275 & -6.652 & 0.376 & -10.479 & -10.166 & -0.314 \\
\hline $\mathrm{X}-\mathrm{X}$ (Diagonal) & 1.380 & -1.569 & 2.949 & 2.698 & -1.443 & 4.142 & -4.706 & -4.581 & -0.125 \\
\hline X-X (Intramolecular) & -8.597 & -12.236 & 3.639 & -11.985 & -12.111 & 0.125 & -17.319 & -18.009 & 0.690 \\
\hline
\end{tabular}

Table S3. Selected donor-acceptor natural bond orbital interactions with their corresponding second-order perturbation stabilization energies in $\mathrm{HHB}$ dimer of $\mathrm{AceCl}_{2}$.

\begin{tabular}{|l|l|l|}
\hline Donor NBO & Acceptor NBO & $\mathrm{E}(2)(\mathrm{kcal} / \mathrm{mol})$ \\
\hline LP (1) Cl1 & $\mathrm{BD} *(1) \mathrm{Cl} 24-\mathrm{C} 33$ & 0.17 \\
\hline LP (2) Cl1 & $\mathrm{BD} *(1) \mathrm{Cl} 24-\mathrm{C} 33$ & 0.07 \\
\hline LP (1) Cl2 & $\mathrm{BD} *(1) \mathrm{Cl} 23-\mathrm{C} 25$ & 0.25 \\
\hline LP (2) Cl2 & $\mathrm{BD} *(1) \mathrm{Cl} 23-\mathrm{C} 25$ & 0.19 \\
\hline LP (1) Cl23 & $\mathrm{BD} *(1) \mathrm{Cl}-\mathrm{C} 11$ & 0.17 \\
\hline LP (2) Cl23 & $\mathrm{BD} *(1) \mathrm{Cl}-\mathrm{C} 11$ & 0.07 \\
\hline LP (1) Cl24 & $\mathrm{BD} *(1) \mathrm{Cl1}-\mathrm{C} 3$ & 0.25 \\
\hline LP (2) Cl24 & $\mathrm{BD} *(1) \mathrm{Cl1}-\mathrm{C} 3$ & 0.19 \\
\hline
\end{tabular}

Table S4. Selected donor-acceptor natural bond orbital interactions with their corresponding second-order perturbation stabilization energies in $\mathrm{HHB}$ dimer of AceClBr.

\begin{tabular}{|l|l|l|}
\hline Donor NBO & Acceptor NBO & $\mathrm{E}(2)(\mathrm{kcal} / \mathrm{mol})$ \\
\hline $\mathrm{BD}(1) \mathrm{Cl} 2-\mathrm{C} 8$ & $\mathrm{BD} *(1) \mathrm{Br} 23-\mathrm{C} 32$ & 0.09 \\
\hline $\mathrm{LP}(1) \mathrm{Br} 1$ & $\mathrm{BD} *(1) \mathrm{Cl} 24-\mathrm{C} 30$ & 0.27 \\
\hline LP (2) Br1 & $\mathrm{BD} *(1) \mathrm{Cl} 24-\mathrm{C} 30$ & 0.34 \\
\hline LP (1) Cl2 & $\mathrm{BD} *(1) \mathrm{Br} 23-\mathrm{C} 32$ & 0.27 \\
\hline LP (2) Cl2 & $\mathrm{BD} *(1) \mathrm{Br} 23-\mathrm{C} 32$ & 0.14 \\
\hline $\mathrm{BD}(1) \mathrm{Cl} 24-\mathrm{C} 30$ & $\mathrm{BD} *(1) \mathrm{Br} 1-\mathrm{C} 10$ & 0.09 \\
\hline LP (1) Br23 & $\mathrm{BD}^{*}(1) \mathrm{Cl} 2-\mathrm{C} 8$ & 0.27 \\
\hline LP (2) Br23 & $\mathrm{BD}^{*}(1) \mathrm{Cl} 2-\mathrm{C} 8$ & 0.34 \\
\hline LP (1) Cl24 & $\mathrm{BD}^{*}(1) \mathrm{Br} 1-\mathrm{C} 10$ & 0.27 \\
\hline LP (2) Cl24 & $\mathrm{BD}^{*}(1) \mathrm{Br} 1-\mathrm{C} 10$ & 0.14 \\
\hline
\end{tabular}


Table S5. Selected donor-acceptor natural bond orbital interactions with their corresponding second-order perturbation stabilization energies in $\mathrm{HHB}$ dimer of $\mathrm{NIBr}_{2} \mathrm{OMe}$.

\begin{tabular}{|c|c|c|}
\hline Donor NBO & Acceptor NBO & $\mathrm{E}(2)(\mathrm{kcal} / \mathrm{mol})$ \\
\hline $\mathrm{BD}(1) \mathrm{C} 1-\mathrm{Br} 40$ & $\mathrm{BD} *(1) \mathrm{C} 53-\mathrm{Br} 79$ & 0.09 \\
\hline $\mathrm{BD}(1) \mathrm{C} 13-\mathrm{Br} 39$ & $\mathrm{BD}^{*}(1) \mathrm{C} 41-\mathrm{Br} 80$ & 0.07 \\
\hline LP (1) Br39 & BD*(1) C41 - Br80 & 0.41 \\
\hline LP (1) Br39 & $\mathrm{BD}^{*}(1) \mathrm{C} 53-\mathrm{Br} 79$ & 0.08 \\
\hline LP (2) Br39 & $\mathrm{BD}^{*}(1) \mathrm{C} 41-\mathrm{Br} 80$ & 0.45 \\
\hline LP (2) Br39 & $\mathrm{BD} *(1) \mathrm{C} 53-\mathrm{Br} 79$ & 0.15 \\
\hline LP (1) Br40 & $\mathrm{BD} *(1) \mathrm{C} 53-\mathrm{Br} 79$ & 0.70 \\
\hline $\mathrm{LP}(2) \mathrm{Br} 40$ & $\mathrm{BD} *(1) \mathrm{C} 53-\mathrm{Br} 79$ & 0.97 \\
\hline $\mathrm{BD}(1) \mathrm{C} 41-\mathrm{Br} 80$ & $\mathrm{BD} *(1) \mathrm{C} 13-\mathrm{Br} 39$ & 0.09 \\
\hline BD (1) C53 - Br79 & $\mathrm{BD} *(1) \mathrm{C} 1-\mathrm{Br} 40$ & 0.07 \\
\hline LP (1) Br79 & $\mathrm{BD} *(1) \mathrm{C} 1-\mathrm{Br} 40$ & 0.41 \\
\hline LP (1) Br79 & BD*(1) C13 - Br39 & 0.08 \\
\hline LP (2) Br79 & $\mathrm{BD} *(1) \mathrm{C} 1-\mathrm{Br} 40$ & 0.45 \\
\hline LP (2) Br79 & $\mathrm{BD} *(1) \mathrm{C} 13-\mathrm{Br} 39$ & 0.15 \\
\hline LP (1) Br80 & $\mathrm{BD} *(1) \mathrm{C} 13-\mathrm{Br} 39$ & 0.70 \\
\hline LP (2) Br80 & $\mathrm{BD} *(1) \mathrm{C} 13-\mathrm{Br} 39$ & 0.97 \\
\hline
\end{tabular}

Table S6. Magnitudes of dipole moments for adjacent dimers of crystal structures.

\begin{tabular}{|c|c|c|}
\hline & & Dipole Moment (Debye) \\
\hline \multirow[t]{3}{*}{$\mathrm{NIBr}_{2} \mathrm{OMe}$} & HHB-dimer & 0.000 \\
\hline & Stacked-dimer & 2.129 \\
\hline & Monomer & 1.127 \\
\hline \multirow[t]{3}{*}{$\mathrm{AceCl}_{2}$} & HHB-dimer & 0.000 \\
\hline & Stacked-dimer & 0.000 \\
\hline & Monomer & 4.540 \\
\hline \multirow[t]{3}{*}{ AceClBr } & HHB-dimer & 0.002 \\
\hline & Stacked-dimer & 0.001 \\
\hline & Monomer & 4.375 \\
\hline
\end{tabular}




\begin{tabular}{|l|l|l|}
\hline \multirow{3}{*}{$\mathbf{N I B r}_{2} \mathbf{P h}$} & Side-dimer & 0.871 \\
\cline { 2 - 3 } & Stacked-dimer & 2.815 \\
\cline { 2 - 3 } & Monomer & 0.768 \\
\hline
\end{tabular}

\section{Figures}

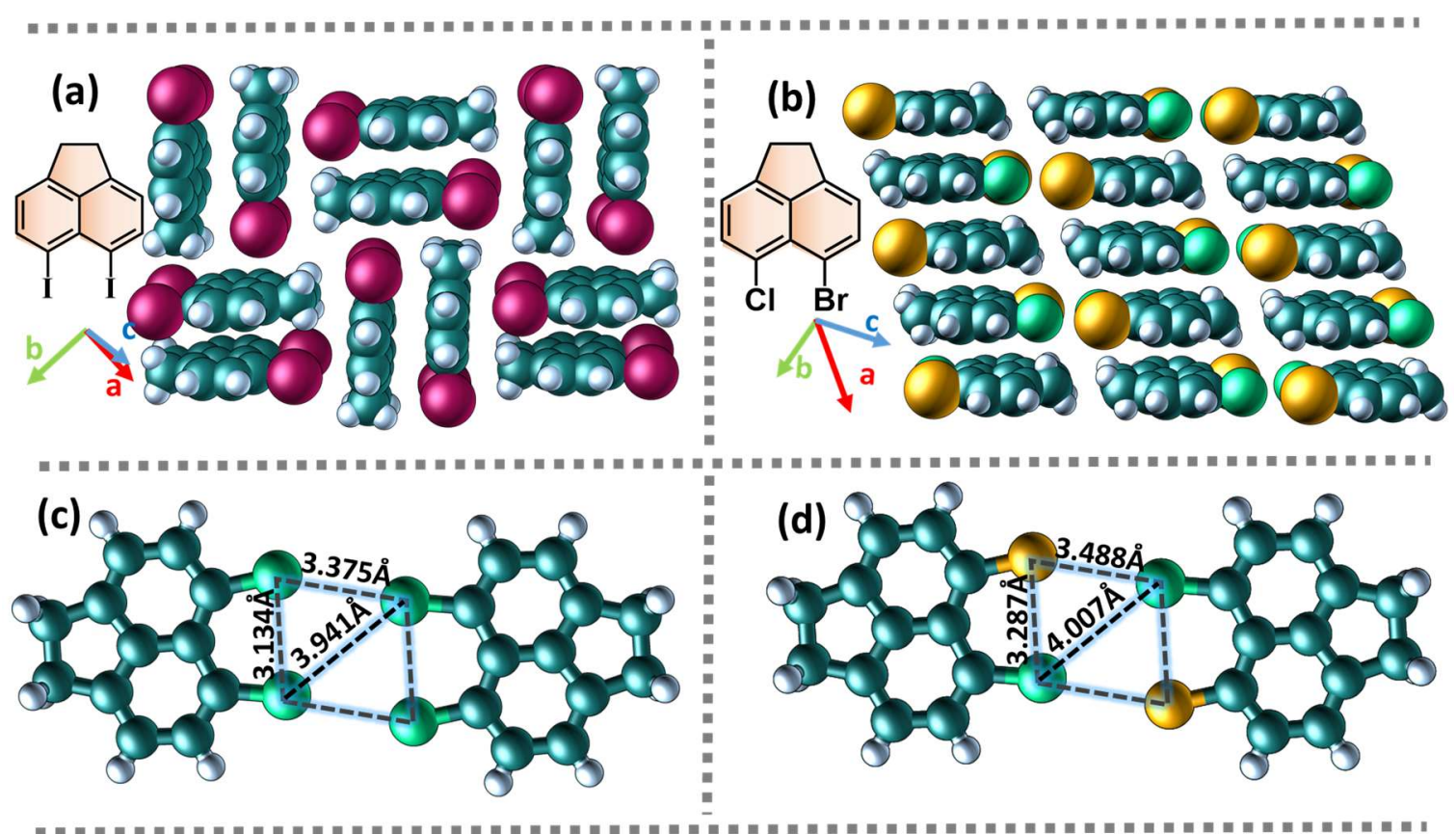

Figure S1. Crystal packing of (a) AceI $\mathrm{I}_{2}$ (Class-1), (b) AceClBr (Class-2). HHB-dimer exhibiting parallelogramtype $\mathrm{X}_{4}$ synthon in (c) $\mathrm{AceCl}_{2}$ and (d) AceClBr. Crystal packing are obtained from previous literature. ${ }^{21,22,23} \mathrm{AceIBr}$ with $\mathrm{I}$ and $\mathrm{Br}$ as peri-halogen substituents also forms Class-1 arrangement. 

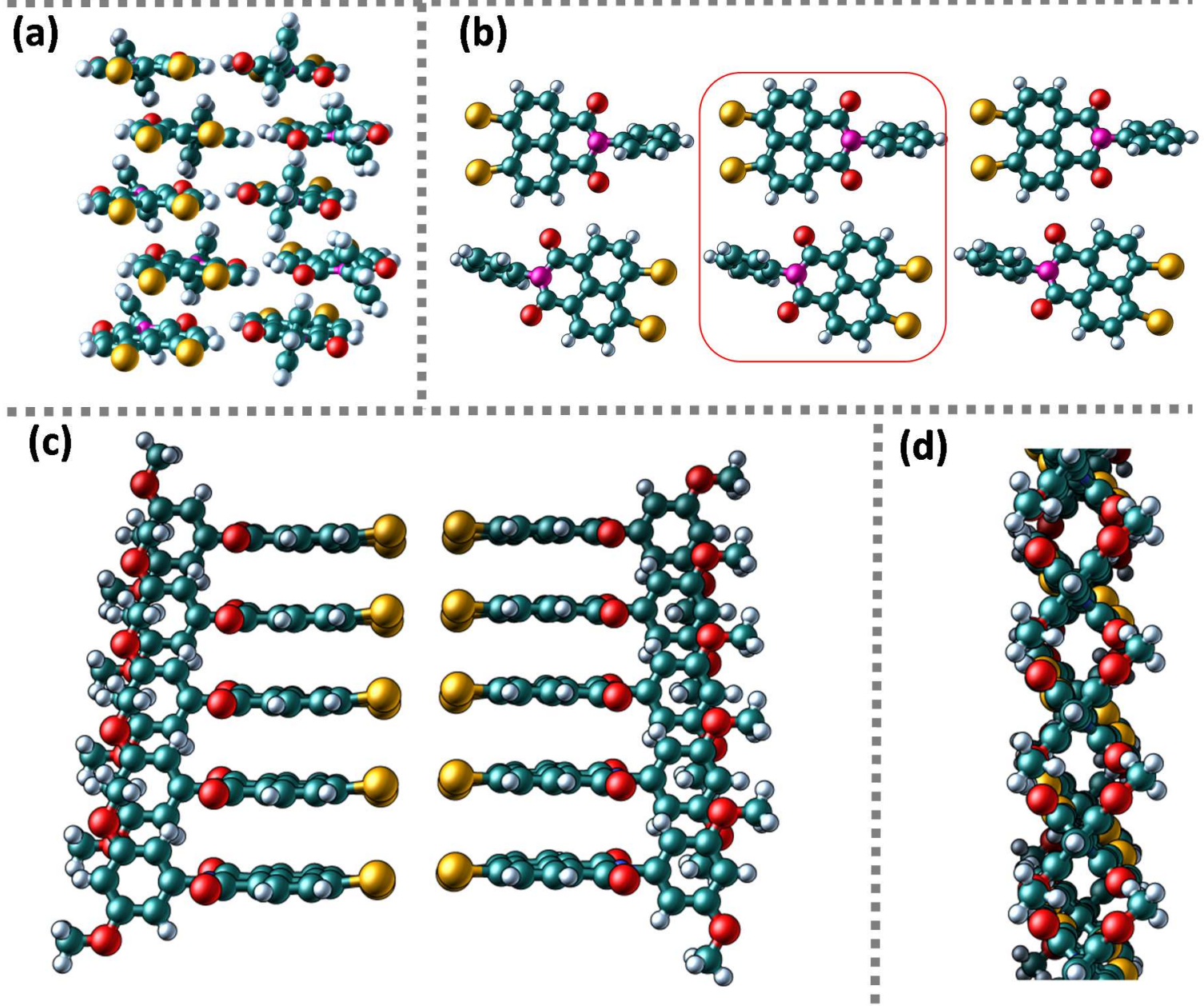

(e)
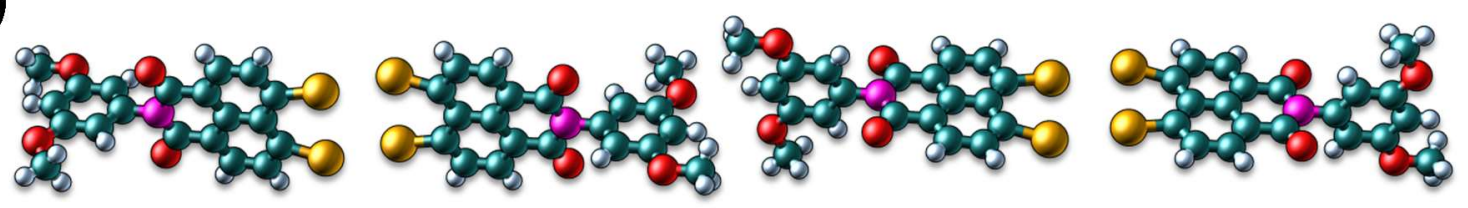

Figure S2. (a) Alternating slip-stacked arrangement and (b) linear arrangement of the side dimer (highlighted with red outline) of $\mathrm{NIBr}_{2} \mathrm{Ph}$ (c) front view and (d) side view of dimeric columns of segregated stacks of $\mathrm{NIBr}_{2} \mathrm{OMe}$ (the mutually perpendicular orientation of the donor and acceptor units are clearly visible as ' $\mathrm{X}$ ' shaped units) (e) $\mathrm{NIBr}_{2} \mathrm{OMe}$ arrays perfectly arranged in a plane as viewed along crystallographic $b$-axis (stacking axis). 
(a)

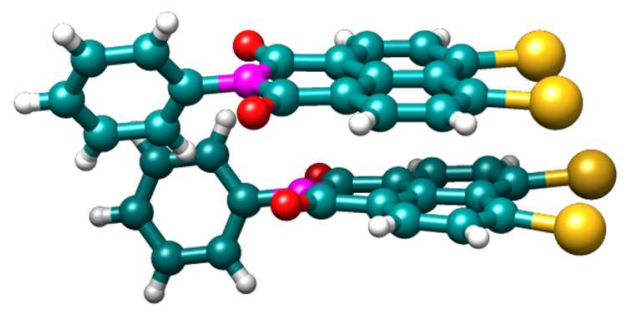

(b)

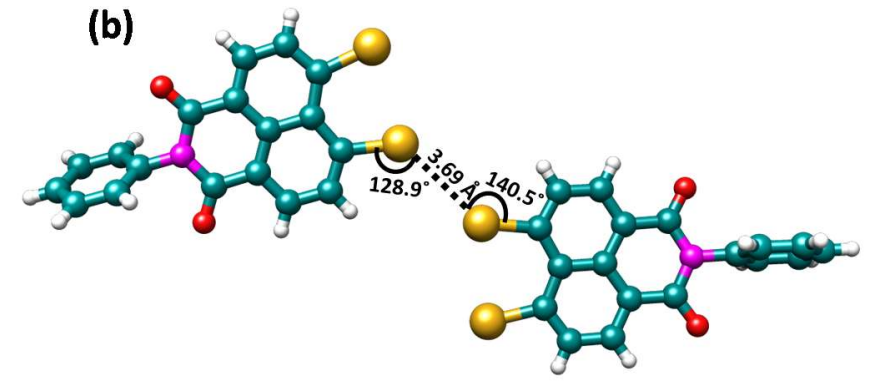

Figure S3. (a) Stacked dimer and (b) one halogen-halogen interaction containing dimer (HHB1) of $\mathrm{NIBr}_{2} \mathrm{Ph}$.
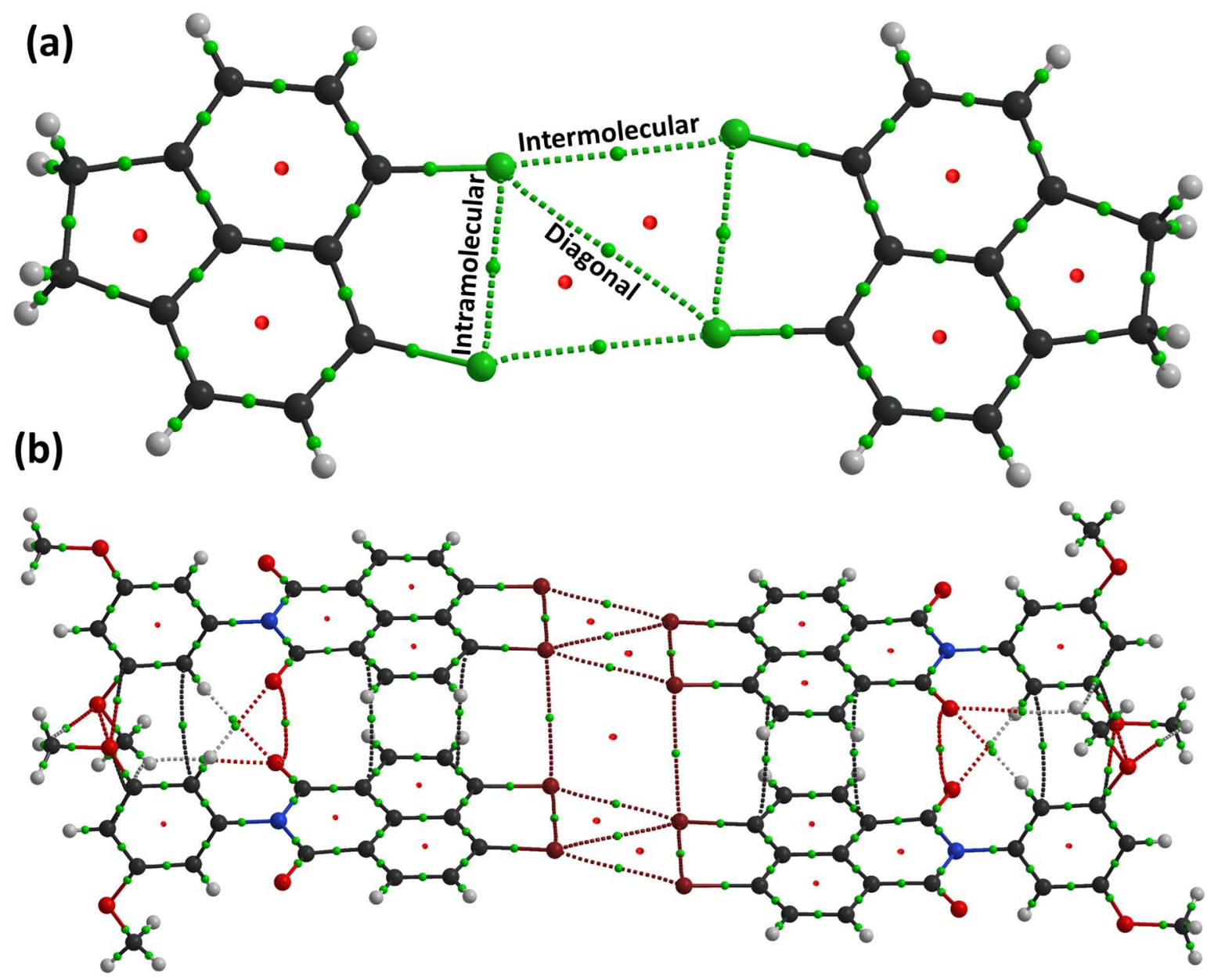

Figure S4. QTAIM electron density maps of (a) $\mathrm{AceCl}_{2}$ HHB-dimer and (b) $\mathrm{NIBr}_{2} \mathrm{OMe}$ tetramer showing parallelogram-type $\mathrm{X}_{4}$ synthons. The green and red dots represent BCPs and RCPs respectively. 

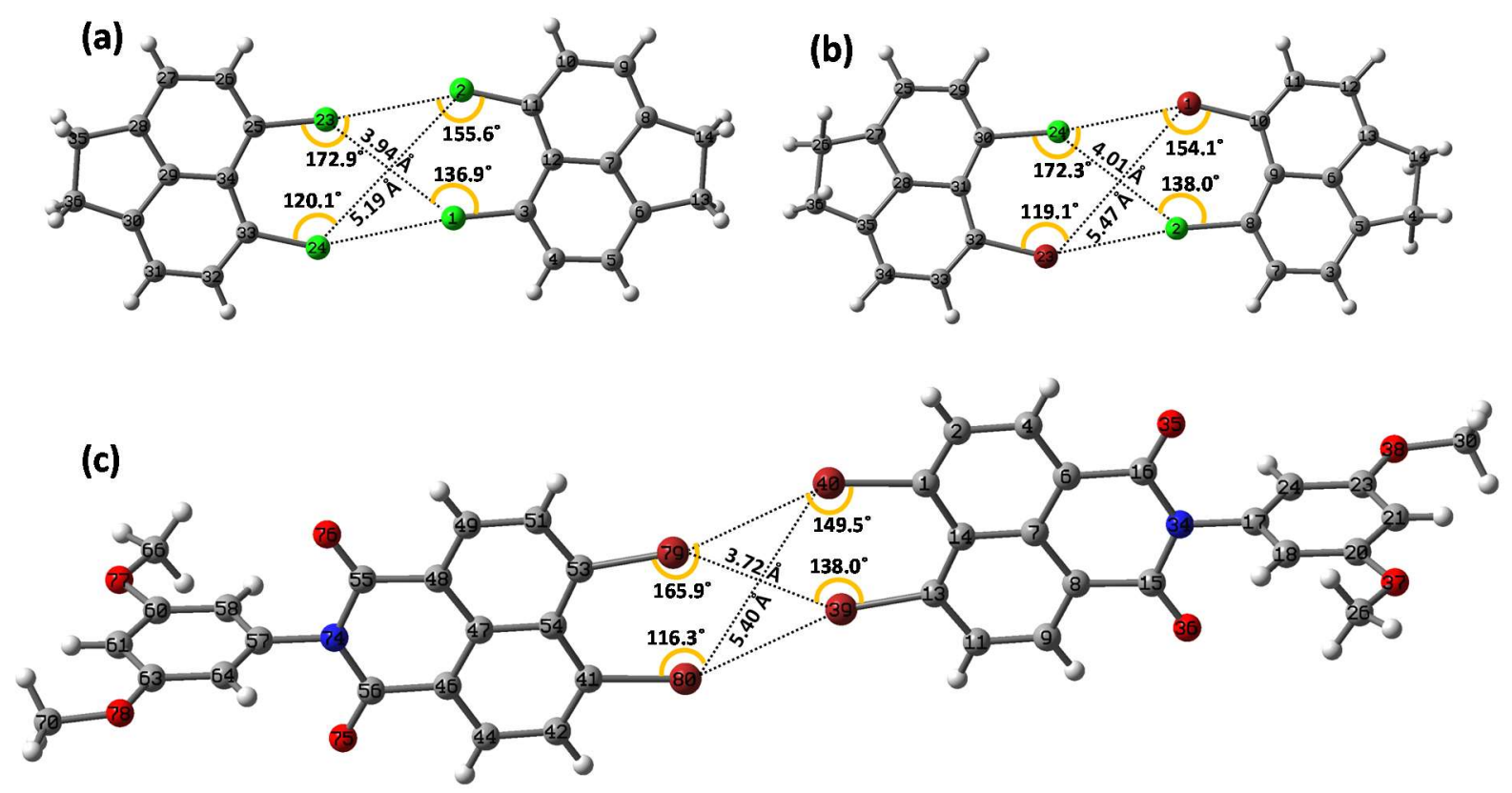

Figure S5. HHB-dimers of (a) $\mathrm{AceCl}_{2}$, (b) $\mathrm{AceClBr}$ and (c) $\mathrm{NIBr}_{2} \mathrm{OMe}$ with atom labels and depicting $\mathrm{C}-\mathrm{X} \cdots \mathrm{X}$ angles.

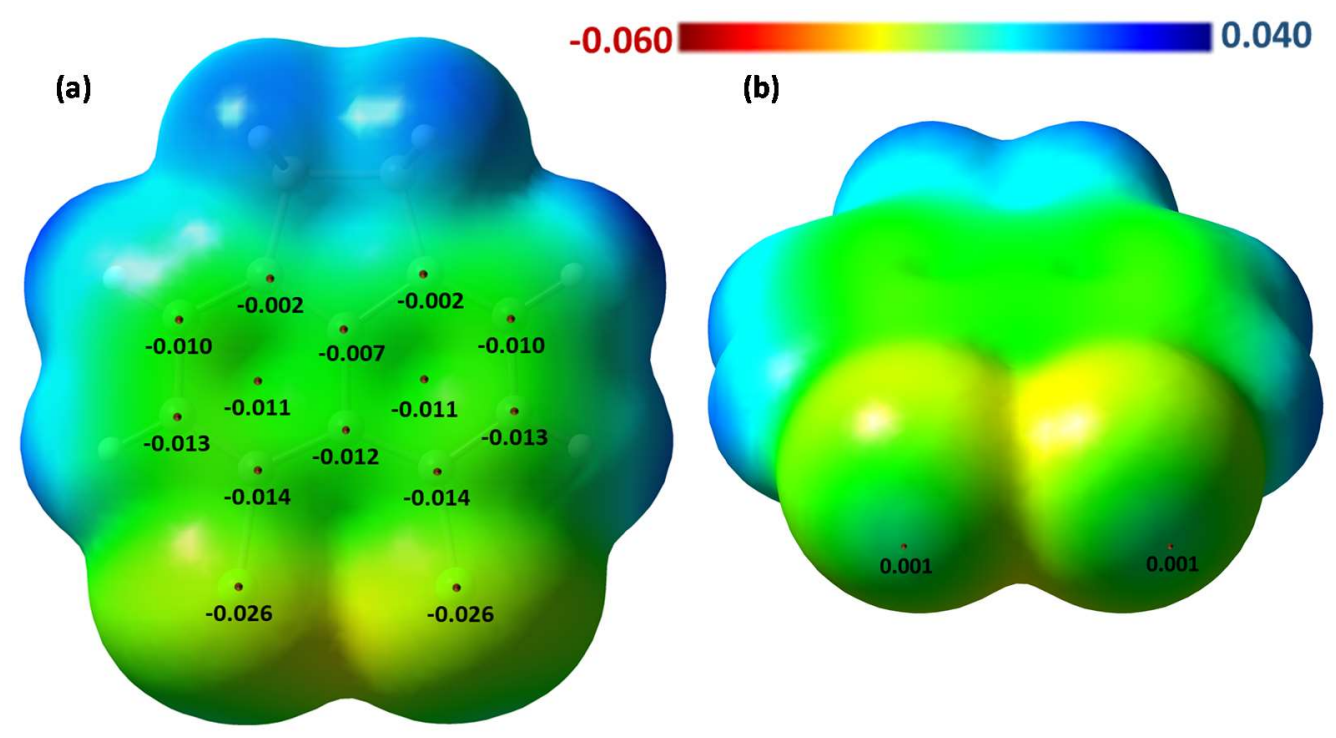



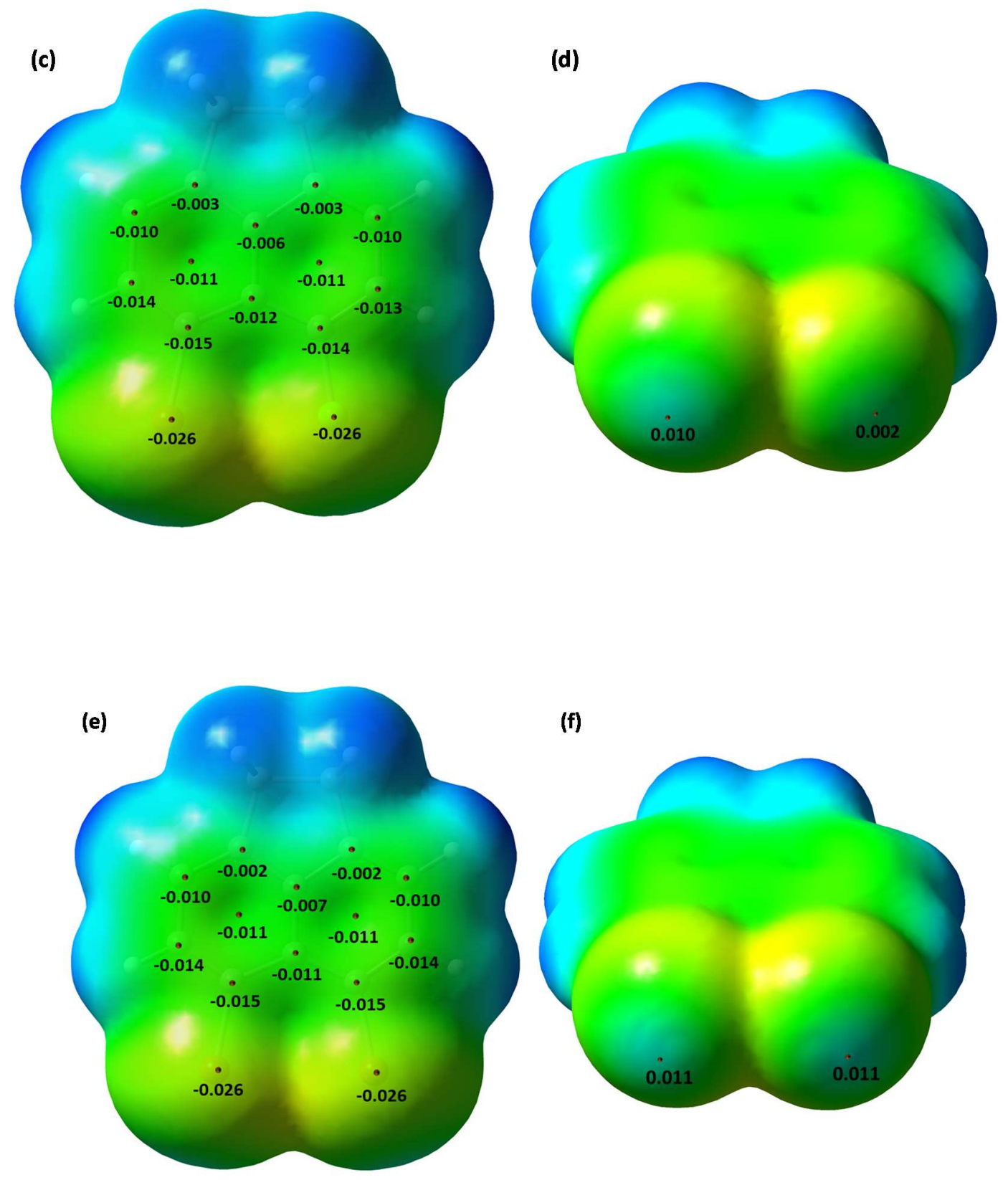

(f)

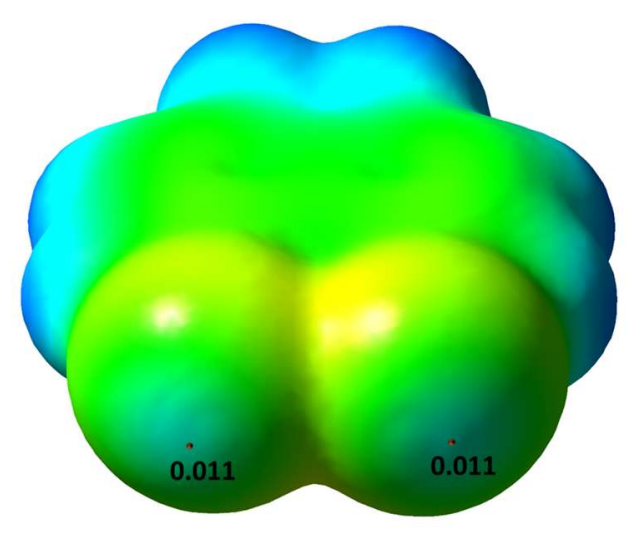



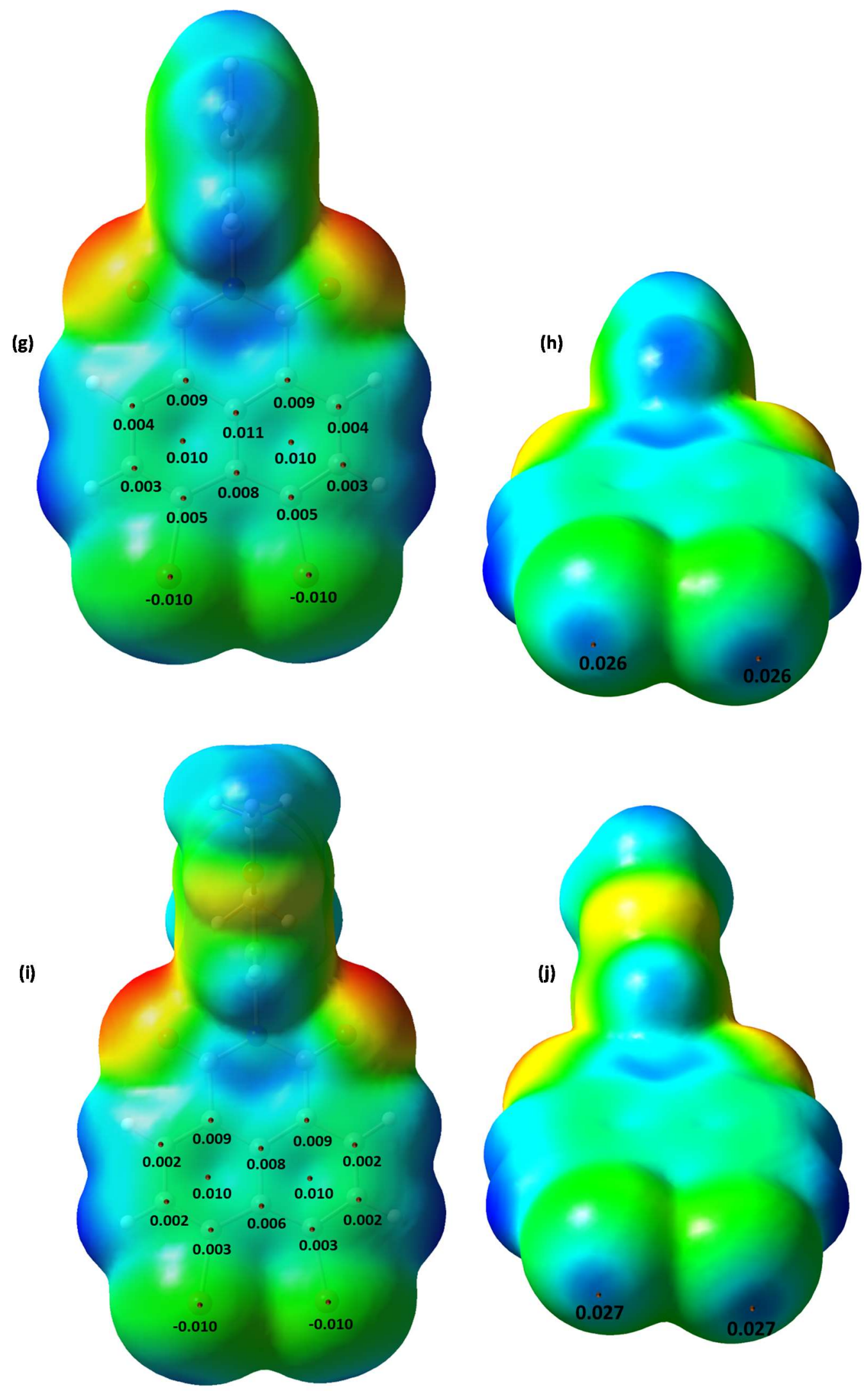

Figure S6. ESP maps (0.001 isodensity surface) of (a-b) $\mathrm{AceCl}_{2}$, (c-d) AceClBr, (e-f) $\mathrm{AceBr}_{2}$, (g-h) $\mathrm{NIBr}_{2} \mathrm{Ph}_{\text {and }}(\mathrm{i}-\mathrm{j}) \mathrm{NIBr} \mathrm{OMe}_{2}$ 
(a)

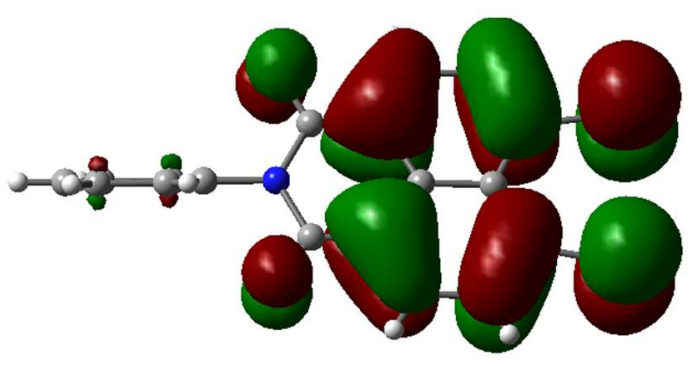

(b)

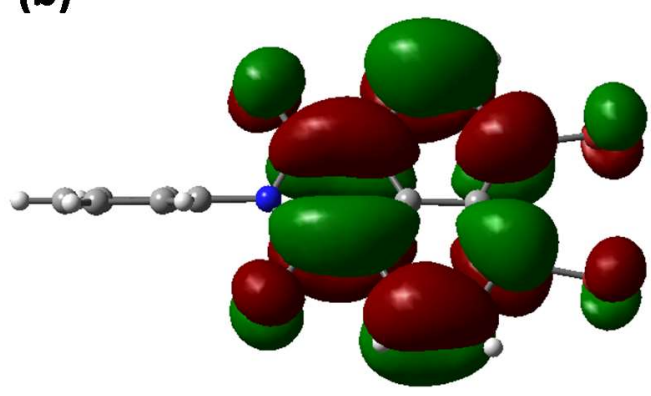

Figure S7. (a) HOMO and (b) LUMO of $\mathrm{NIBr}_{2} \mathrm{Ph}$ monomer (isosurface value 0.02).

(a)
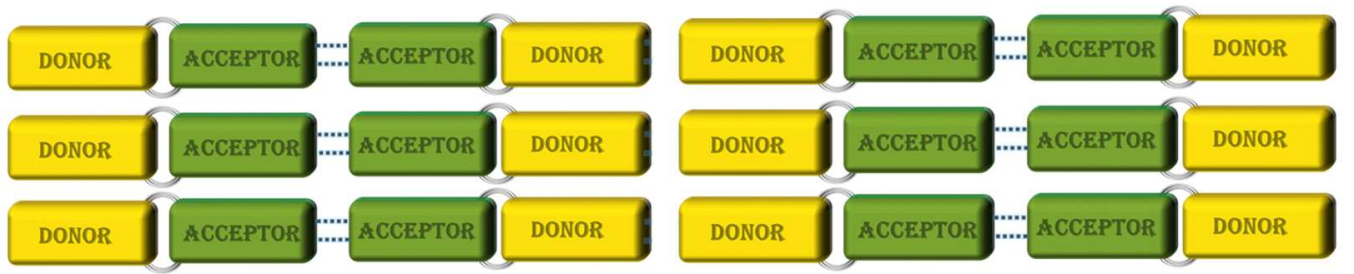

(b)

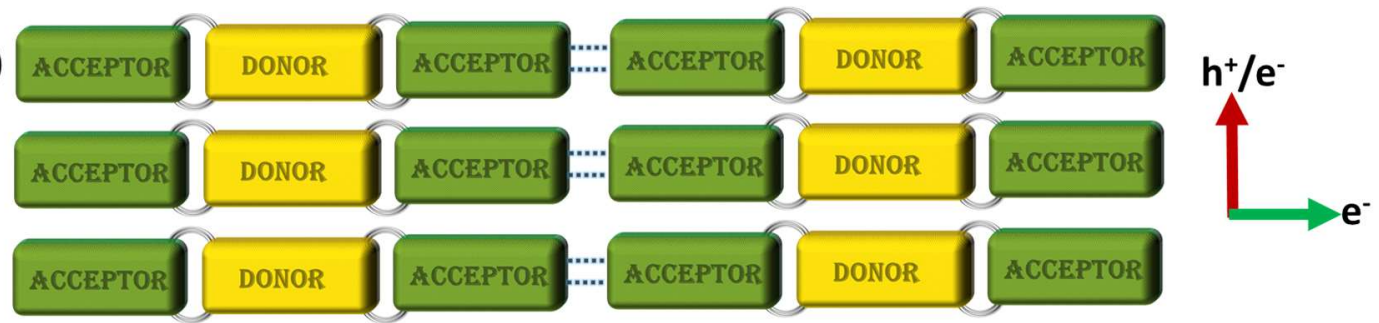

(c)

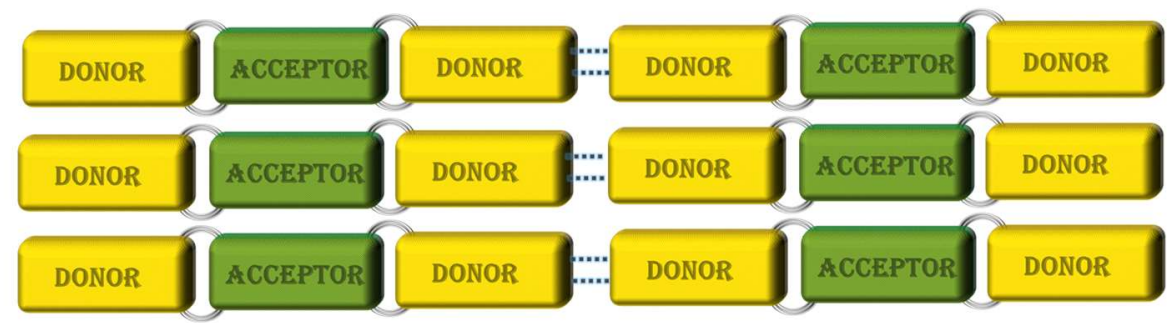

Scheme S1. (a) Donor-acceptor arrangement in $\mathrm{NIBr}_{2} \mathrm{OMe}$, (b) symmetric connected acceptor-donor-acceptor (A-DA) packing that can facilitate continuous electron mobility and (c) donor-acceptor-donor (D-A-D) arrays promoting hole mobility perpendicular to the stacking direction (depicted as red arrow). The blue dotted lines indicate strong intermolecular contacts that facilitate better orbital overlap like $\mathrm{X} \bullet \bullet \mathrm{X}$ bonding.

\section{References}

(1) Shoyama, K.; Schmidt, D.; Mahl, M.; Würthner, F. Electron-Poor Bowl-Shaped Polycyclic Aromatic Dicarboximides: Synthesis, Crystal Structures, and Optical and Redox Properties. Org. Lett. 2017, 19, 5328-5331.

(2) Uersfeld, D.; Stappert, S.; Li, C.; Müllen, K. Practical Syntheses of Terrylene Chromophores from Naphthalene and Perylene Building Blocks. Adv. Synth. Catal. 2017, 359, 4184-4189.

(3) Sheldrick, G., A short history of SHELX. Acta Cryst. A 2008, 64, 112-122.

(4) Farrugia, L. J. WinGX Suite for Small-Molecule Single-Crystal Crystallography. J. Appl. Crystallogr. 1999, 32, 837-838.

(5) Bruno, I. J.; Cole, J. C.; Edgington, P. R.; Kessler, M.; Macrae, C. F.; McCabe, P.; Pearson, J.; Taylor, R. New Software for Searching the Cambridge Structural Database and Visualizing Crystal Structures. Acta Crystallogr., Sect. B 2002, 58, 389-397.

(6) Aragó, J.; Sancho-García, J. C.; Ortí, E.; Beljonne, D. Ab Initio Modeling of Donor-Acceptor Interactions and Charge-Transfer Excitations in Molecular Complexes: The Case of Terthiophene- 
Tetracyanoquinodimethane. J. Chem. Theory Comput. 2011, 7, 2068-2077.

Gaussian 16, Revision C.01, Frisch, M. J.; Trucks, G. W.; Schlegel, H. B.; Scuseria, G. E.; Robb, M. A.; Cheeseman, J. R.; Scalmani, G.; Barone, V.; Petersson, G. A.; Nakatsuji, H.; Li, X.; Caricato, M.; Marenich, A. V.; Bloino, J.; Janesko, B. G.; Gomperts, R.; Mennucci, B.; Hratchian, H. P.; Ortiz, J. V.; Izmaylov, A. F.; Sonnenberg, J. L.; Williams-Young, D.; Ding, F.; Lipparini, F.; Egidi, F.; Goings, J.; Peng, B.; Petrone, A.; Henderson, T.; Ranasinghe, D.; Zakrzewski, V. G.; Gao, J.; Rega, N.; Zheng, G.; Liang, W.; Hada, M.; Ehara, M.; Toyota, K.; Fukuda, R.; Hasegawa, J.; Ishida, M.; Nakajima, T.; Honda, Y.; Kitao, O.; Nakai, H.; Vreven, T.; Throssell, K.; Montgomery, J. A., Jr.; Peralta, J. E.; Ogliaro, F.; Bearpark, M. J.; Heyd, J. J.; Brothers, E. N.; Kudin, K. N.; Staroverov, V. N.; Keith, T. A.; Kobayashi, R.; Normand, J.; Raghavachari, K.; Rendell, A. P.; Burant, J. C.; Iyengar, S. S.; Tomasi, J.; Cossi, M.; Millam, J. M.; Klene, M.; Adamo, C.; Cammi, R.; Ochterski, J. W.; Martin, R. L.; Morokuma, K.; Farkas, O.; Foresman, J. B.; Fox, D. J. Gaussian, Inc., Wallingford CT, 2016.

(8) Dennington, R.; Keith, T.; Millam, J. GaussView, Version 5.0.8; Semichem Inc.: Shawnee Mission KS, 2009.

(9) Bader, R. F. W. A Quantum Theory of Molecular Structure and Its Applications. Chem. Rev. 1991, 91, 893-928.

(10) Blanco, M. A.; Pendás, A. M.; Francisco, E. Interacting Quantum Atoms: A Correlated Energy Decomposition Scheme Based on the Quantum Theory of Atoms in Molecules. J. Chem. Theory Comput. 2005, 1, 1096-1109.

(11) Reed, A. E.; Curtiss, L. A.; Weinhold, F. Intermolecular Interactions From A Natural Bond Orbital, Donor-Acceptor Viewpoint. Chem. Rev. 1988, 88, 899-926.

(12) Weinhold, F. Natural Bond Orbital Analysis: A Critical Overview of Relationships to Alternative Bonding Perspectives. J. Comput. Chem. 2012, 33, 2363-2379.

(13) NBO Version 3.1, E. D. Glendening, A. E. Reed, J. E. Carpenter, and F. Weinhold.

(14) Wang, H.; Wang, W.; Jin, W. J. $\sigma$-Hole Bond vs $\pi$-Hole Bond: A Comparison Based on Halogen Bond. Chem. Rev. 2016, 116, 5072- 5104.

(15) Deng, W. Q.; Goddard, W. A. Predictions of Hole Mobilities in Oligoacene Organic Semiconductors from Quantum Mechanical Calculations. J. Phys. Chem. B 2004, 108, 8614-8621.

(16) Hush, N. S. Adiabatic Theory of Outer Sphere Electron-Transfer Reactions in Solution. Trans. Faraday Soc. 1961, 57, 557-580.

(17) Hush, N. S. Adiabatic Rate Processes at Electrodes. I. Energy-Charge Relationships. J. Chem. Phys. 1958, 28, 962-972.

(18) Marcus, R. A. On the Theory of Oxidation-Reduction Reactions Involving Electron Transfer. I. J. Chem. Phys. 1956, 24, 966-978.

(19) GitHub - JoshuaSBrown/QC_Tools: This small repository provides functionality for calculating the charge transfer integrals between two molecules. https://github.com/JoshuaSBrown/QC Tools.

(20) Deng, W. Q.; Sun, L.; Huang, J. D.; Chai, S.; Wen, S. H.; Han, K. L. Quantitative Prediction of Charge Mobilities of $\pi$-Stacked Systems by First-Principles Simulation. Nat. Protoc. 2015, 10, 632-642.

(21) Niyas, M. A.; Ramakrishnan, R.; Vijay, V.; Sebastian, E.; Hariharan, M. Anomalous Halogen-Halogen Interaction Assists Radial Chromophoric Assembly. J. Am. Chem. Soc. 2019, 141, 4536-4540.

(22) Avoyan, R. L.; Struchkov, Y. T. Steric Hindrance and Molecular Conformation. Pt. 8. Crystal and Molecular Structure of 3-Chloro-5-Bromoacenaphthene. J. Struct. Chem. 1964, 5, 378-389.

(23) Aschenbach, L. K.; Knight, F. R.; Randall, R. A. M.; Cordes, D. B.; Baggott, A.; Bühl, M.; Slawin, A. M. Z.; Woollins, J. D. Onset of Three-Centre, Four-Electron Bonding in Peri-Substituted Acenaphthenes: A Structural and Computational Investigation. Dalt. Trans. 2012, 41, 3141-3153. 